\title{
Definitions and Usage, or a Rose by Any Other Name Smells as Sweet
}

\author{
Kurt Salzinger \\ Polytechnic University
}

\begin{abstract}
Who is right - the scientist with his/her definition hewed precisely to mean but one thing or Humpty Dumpty who wills each word to mean whatever he chooses?

As behavior analysts, we all know from bitter experience that people, and that includes scientists, adapt their language to mean whatever they find convenient. Skinner in some of his writing implied that people's sloppy usage is a kind of homecoming party when one can once more indulge oneself in using four-letter words, like "mind." But basically, what happens is that the choice of words and their meanings are functionally determined and that is something we, of all people, should appreciate. The question about misnomers or misuse of words to the detriment of the field, as the author points out, then becomes one of finding the proper reinforcement contingency to control their proper use.
\end{abstract}

We do not, for example, as all of us who are appalled by the misrepresentation of behavior analysis in introductory psychology textbooks well know, control the reinforcement contingency of textbook writers and they, unlike lay people, are in our general field of endeavor. Now we are finding that behavior analysts are using the term "nonaversive" in what the author calls a subjective manner. The problem may well be a matter of finding out the reinforcement contingency at work here. I believe those who use the term "nonaversive" to describe their therapeutic work, do so to separate themselves from those techniques that lay people reject as consisting of cruelty or pain. Communicating with lay people is not a trivial part of the work of those who administer treatment. Both the patients and those who care for them are typically lay people. They know relatively little about our functional definitions; what is more, they are much more con- cerned about saving their children than worrying about functional definitions of terms.

In one very important sense, lay people are observing the functional definition of the term nonaversive as are the psychologists who use that term. Some behavior management techniques appear on their face to be cruel and unusual punishment. Both therapists and lay people want to be assured that their children will not be exposed to such things, regardless of what they are called. In that sense they are using a functional definition of "aversive," that is, any event that strengthens their behavior of removing their child from such treatment. I don't believe that the criterion of objectivity is the appropriate one for this problem. What is appropriate here is the criterion of functionality of the definition. What remains then is that we decide on a term understandable to the lay person that conveys the message that, as therapists, we are not going to use treatments of that quality (pain, unpleasantness) to which we would not permit our own children to be subjected.

I don't believe that exhortations will help much without those contingencies. One way to change the word usage successfully is to suggest a term less aversive (so to speak) to behavior analysts and more acceptable to therapists and lay people. Perhaps we should employ a term such as the medical field uses, namely "heroic" treatment. People are already familiar with the general meaning of that word in this context and by using that instead of the technical term, "aversive," we would not be contaminating our scientific language.

In the long run, however, we must remember that a thorn by any other name hurts as much. 